\title{
Computed Tomography-Guided Percutaneous Cryoablation for Subcardiac Hepatocellular Carcinoma: Safety, Efficacy, Therapeutic Results and Risk Factors for Survival Outcomes
}

This article was published in the following Dove Press journal:

Cancer Management and Research

\section{Chunhou $\mathrm{Qi}^{1}$ \\ Hongfei Gao' \\ Qinghua Zhao ${ }^{2}$ \\ Lei Zhang ${ }^{3}$}

'Department of Interventional Medicine, Linyi City Central Hospital, Yishui, Shandong, People's Republic of China; ${ }^{2}$ Department of Emergency Medicine, Yishui County People's Hospital, Yishui, Shandong, People's Republic of China; ${ }^{3}$ Department of Interventional Radiology, Shandong Medical Imaging Research Institute, Affiliated to Shandong University, Jinan, Shandong, People's Republic of China
Correspondence: Lei Zhang Department of Interventional Radiology, Shandong Medical Imaging Research Institute, Affiliated to Shandong University, 324 Jingwu Road, Jinan, Shandong, People's Republic of China Tel +86-53I-68776767

Fax +86-53I-87938550

Email zhanglei0422@yeah.net
Objective: To investigate the clinical safety, efficacy, therapeutic outcomes and risk factors of computed tomography-guided percutaneous cryoablation (CT-PCRA) for subcardiac hepatocellular carcinoma (HCC).

Patients and Methods: In this study, patients with single HCC nodules located on the left lobe who subsequently underwent CT-PCRA were reviewed from July 2012 to August 2016. According to the definition of subcardiac HCC, the patients were grouped into the subcardiac HCC group ( $n=33)$ and the non-subcardiac HCC group $(n=40)$. The technical success rates, tumour response rates, oncological outcomes including overall survival (OS) and recurrencefree survival (RFS) and complications were compared. Multivariate analysis was performed on clinicopathological variables to identify factors affecting long-term outcomes.

Results: Seventy-three patients with subcardiac HCC were included in this study. After a median follow-up time of 37.8 months, $27.4 \%$ (20/73) of the patients died. The technical success and complete response rates were not significantly different between the two groups $(p=1.000 ; p=$ 0.590). The cumulative OS and RFS of the subcardiac HCC group were comparable to those of the non-subcardiac HCC group ( $\mathrm{p}=0.820, \mathrm{p}=0.922$ ). Two major complications, intra-abdominal bleeding and right pleural effusion, were found at 2.2 and 3.1 months in the subcardiac HCC group, which were comparable with those in the non-subcardiac HCC group ( $p=0.683$ ). The multivariate analysis results showed that older age (hazard ratio [HR]: 2.382, 95\% confidence interval [CI]: 1.884-7.823; $\mathrm{p}=0.038$ ) and ALBI grade 2-3 (HR: 3.398, 95\% CI: 1.950-6.058; $\mathrm{p}=$ 0.021 ) may be predictors of poor OS and that tumour size $\geq 3 \mathrm{~cm}$ in diameter (HR: $3.302,95 \% \mathrm{CI}$ : $2.232-8.293 ; \mathrm{p}=0.012$ ) may be a predictor of poor RFS.

Conclusion: CT-PCRA for subcardiac HCC can be performed safely and efficiently and contribute to improving survival prognosis.

Keywords: cryoablation, subcardiac location, hepatocellular carcinoma, therapeutic outcomes, risk factors

\section{Introduction}

Hepatocellular carcinoma (HCC) resulting from hepatitis B virus (HBV) has become one of the most serious life-threatening diseases, with morbidity and mortality increasing in the last twenty years. ${ }^{1-3}$ The Barcelona Clinic Liver Cancer (BCLC) guidelines recommend first-line treatment options for early-stage HCC, mainly including liver transplantation, surgical resection and local radical 
ablation. $^{4,5}$ In particular, as a minimally invasive and easily repeatable treatment technique, thermal ablation is a promising and alternative option for unresectable HCC. ${ }^{6-8}$ However, the difficulty of controlling the thermal field range and low puncture accuracy can easily cause damage to peripheral organs. Therefore, a precise and cautious operation is essential to remove these tumours in challenging locations (eg, subcapsular and perivascular locations). ${ }^{9,10}$ Cryoablation (CRA) has become one of the most effective locoregional therapies in HCC, presenting various advantages, ${ }^{11-13}$ including the lack of serious damage to large blood vessels, the development of a visual ice ball activation of cryoimmunology in cancer and the absence of an association with severe pain. Most studies have reported that CRA has comparable outcomes to radiofrequency ablation (RFA) or microwave ablation (MWA) for HCC. ${ }^{14,15}$ Nevertheless, there are controversies in the comparison between CRA and the two other types of heat-induced ablation for HCC treatment in complex locations.

Previous studies have addressed the limitation of RFA for subcapsular HCC regarding local tumour control. ${ }^{16-18}$ Among the several subcapsular locations of HCC, the subcardiac location is a well-known high-risk site due to its proximity to the heart. Therefore, the ablation zone may come into contact with the heart, which can result in mechanical damage or burns. Cha. et al ${ }^{19}$ compared the use of RFA for subcardiac and non-subcardiac HCC treatment to assess risk factors and technical failures. These authors pointed out that RFA is an effective and secure treatment for subcardiac HCC. However, CRA is an easier ablation method to control than RFA, mainly due to its discernible ablation boundary. Thus, CRA may also achieve similar outcomes and effects in subcardiac HCC.

The present study aims to evaluate the clinical safety, efficacy, therapeutic outcomes and risk factors of computed tomography-guided percutaneous cryoablation (CTPCRA) for subcardiac HCC treatment. Moreover, this study also highlights CT-PCRA as a new treatment option for HCC ablation in this particular location.

\section{Patients and Methods}

\section{Patients}

The data related with CT-PCRA for subcardiac HCC is confidentiality. The study was carried out according to the ethical principles of the Helsinki Declaration and protocol was approved by the ethics committee of Linyi City Central
Hospital. Due to the retrospective nature of this study, the requirement of patient consent for inclusion was waived. All medical cases of newly diagnosed HCC patients were evaluated in multidisciplinary meetings that included interventional radiologists, pathologists, hepatologists and oncologists to determine treatment methods, including liver transplantation, surgical resection, local thermal ablation, transarterial chemoembolization (TACE) and targeted chemotherapy (ie, sorafenib or lenvatinib). The study cohort consisted of 678 consecutive HCC patients who met the HCC diagnostic criteria, as defined by the American Association for the Study of Liver Diseases. All of the patients underwent computed tomographyguided percutaneous cryoablation (CT-PCRA) as the first treatment between July 2012 and August 2016, and their medical data were reviewed. The reasons for choosing CTPCRA instead of surgical resection (SR) were as follows: (1) insufficient liver remnant; (2) psychological resistance to invasive treatment; and (3) refusal of general anaesthesia. The inclusion criteria for the cohort included the following parameters: (a) HCC lesions located on the left lobe; (b) a unique tumour with a maximum size of less than $5 \mathrm{~cm}$ and 2-3 tumours smaller than $3 \mathrm{~cm}$; (c) absence of major vascular invasion or extrahepatic metastasis; and (d) Child-Pugh classification A or B. The exclusion criteria for the cohort were as follows: (a) severe medical comorbidities, including cardiac, pulmonary and renal dysfunctions; (b) serious clotting disorders (ie, platelet count $<50$ cells $\times 10^{9} \mathrm{~L}^{-1}$, prothrombin activity $<40 \%$ and prothrombin time $>25 \mathrm{~s}$ ); (c) serious active infection; and (d) loss to follow-up. Based on the inclusion and exclusion criteria, 73 patients (60 men and 13 women; average age of 58.6 years and mean tumour size of $2.6 \pm 0.7 \mathrm{~cm}$ ) with 73 nodules submitted to CT-PCRA were selected for inclusion in this study. This method was used to identify patients undergoing CT-PCRA for subcardiac HCC according to electronic medical records and imaging reports. Two radiologists with 8 years of abdominal image analysis experience who were blinded to the clinical outcomes reviewed the HCC images manually. They used a communication system (PACS) and image archive to identify subcardiac HCC cases.

\section{Subcardiac HCC Definition}

Subcardiac HCC was defined as an index tumour in coronal or axial images on preablation imaging situated approximately $1 \mathrm{~cm}$ from the pericardium. ${ }^{19}$ The following data was extracted: (a) direction of the CRA electrode while 
inserting; (b) the shortest distance between the heart and index tumour. The distance between the heart and the tumour was determined from the lateral margin of the tumour to the nearest pericardium. According to the definition of subcardiac HCC, the patients included in the cohort were grouped into a subcardiac HCC group $(n=33)$ and a non-subcardiac HCC group $(n=40)$. Figure 1 shows the patient enrolment pathway, along with the inclusion and exclusion criteria.

\section{Equipment and CRA Procedure}

The TACE procedures were performed with the Allura Xper FD 20 (Philips Healthcare, Best, Amsterdam, The Netherlands) digital subtraction angiography (DSA) instrument. A 16-slice spiral computed tomography (CT) scanner (Brilliance CT BigBore; Phillip Medical Systems, The Netherlands) was used for cryoablation puncture guidance and image acquisition. The Cryo-HitTM (Galilmedical, Israel) system was used to perform cryoablation using argon gas as a cryogen. Consumables included the angiography catheter, the artery catheter sheath, the puncture needle (Terumo, Tokyo, Japan), gelatine sponge particles (Alicon, Hangzhou, China), lipiodol (Lipiodol Ultrafluide; Guerbet, Aulnay-Sous-Bois, France), the micro-catheter (Terumo, Tokyo, Japan) and chemotherapeutics including epirubicin (Shenzhen Main Luck Pharmaceuticals,
Shenzhen, China) and lobaplatin (Chang'an International Pharmaceutical, Hainan, China). Before the CRA procedure, the patients were deeply sedated, and a thin metallic marker was set on the surface of the body over the target tumour with the patient in the supine position. A simple CT scan was performed first to verify the puncture path and the localization of the target lesion. The puncture site was anaesthetized with $2 \%$ lidocaine, and then a CRA electrode probe was introduced along the pathway to reach the opposite edge of the tumour lesion through its centre. The numbers and placement of cryoprobes, the time of ablation and the appropriate approach were established based on the size and shape of the tumour and on obtaining a visible "ice ball". The tumour was frozen at a maximum flow rate for approximately 15 minutes, thawed for 5 minutes and then frozen again for more than 15 minutes. The cryoprobes were removed after the temperature of the electrode tip reached a temperature above $0{ }^{\circ} \mathrm{C}$. The purpose of this treatment was cytoreduction to ablate the largest amount of viable residual tumour to control its growth. The viable residual tumour was evaluated using contrast-enhanced CT or magnetic resonance imaging (MRI). After treatment with CRA, antiinflammatory, liver protective, and symptomatic treatments were prescribed. We present one case of CT-PCRA for subcardiac HCC in Figure 2.

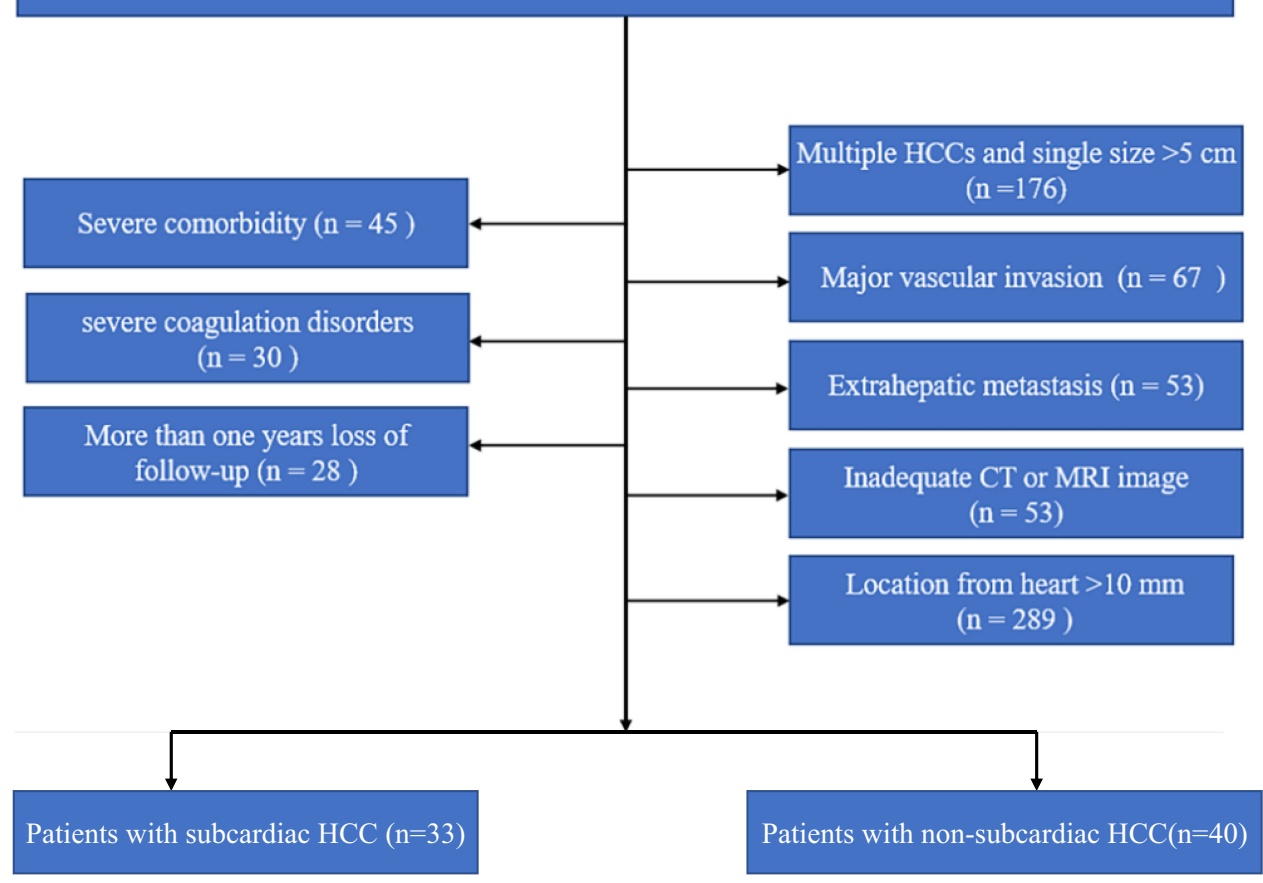

Figure I Flow diagram shows study patient accrual process. 

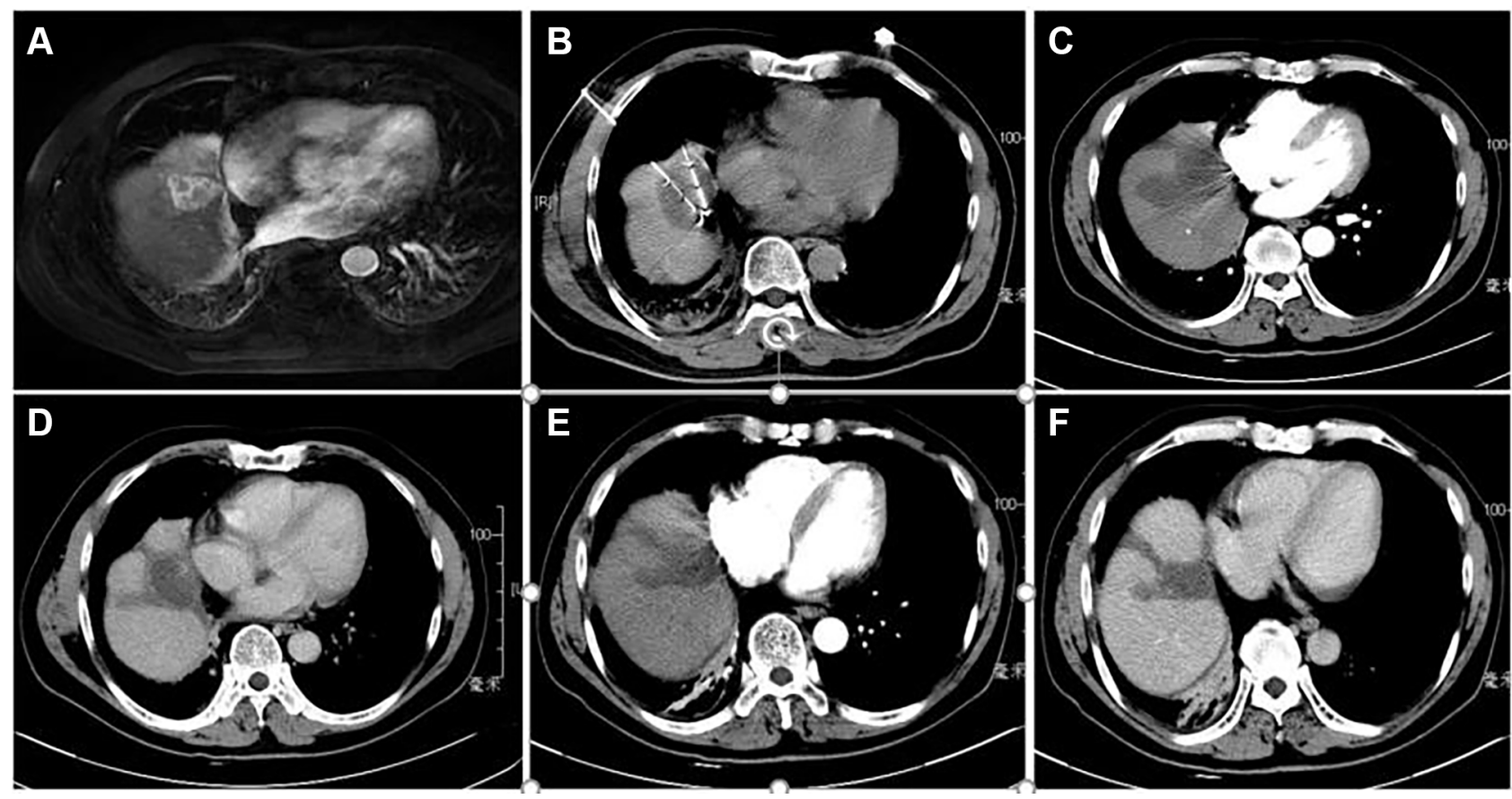

Figure 2 Contrast-enhanced computed tomography (CT) revealed a $\mathrm{HCC}$ of $3.7 \mathrm{~cm}$ in maximum diameter adjacent to heart in segment 4 of a $57-y e a r-o l d$ woman with liver cirrhosis caused by hepatitis B. (A) CT axial scan showed a high density round nodule adjacent to heart in segment 4 in arterial phase; (B) two CRA electrode probes were inserted into subcardiac HCC inside under CT guidance; (C) a clear ice-ball covered in HCC nodule is shown in arterial phase CT image after CRA; (D) low density CRA zone is shown in plain CT image after 3 months; (E) low density CRA zone is shown in arterial phase CT image after 3 months; (F) low density CRA zone is shown in delay phase CT image after 3 months.

\section{Data Collection}

Clinicopathological data were collected, including sex, age, hepatitis B surface antigen, tumour amount and size, ChildTurcotte-Pugh (CTP) grade, AFP, albumin, aspartate aminotransferase (AST), alanine aminotransferase (ALT), total bilirubin, international normalized ratio (INR), platelet count, TACE sessions, CRA sessions, and albuminbilirubin (ALBI) grade. ALBI grade is a novel method used for the evaluation of hepatic function. In comparison with the CTP classification, the ALBI grade eliminates subjective variables, such as ascites and encephalopathy. ${ }^{20}$ The ALBI score was calculated before treatment using the appropriate clinical parameters as follows: (log 10 bilirubin [BI] $[\mu \mathrm{mol} / \mathrm{L}] \times 0.66)+($ albumin $[\mathrm{AL}][\mathrm{g} / \mathrm{L}] \times-0.085)$; grade 1,2 , and $3=\leq-2.60,>-2.60$ to -1.39 , and $>-1.39$, respectively.

\section{Assessment and Follow-Up}

Follow-ups were performed at one and three months after treatment and then at approximately 3-6 month intervals. Thereafter, the follow-up visits covered several evaluations, including routine physical examination, laboratory tests (such as total bilirubin, serum albumin, prothrombin time and tumour marker levels), and contrast-enhanced imaging including CT or MRI. Technique success was defined as the absence of contrast enhancement on imaging in any area of the mass after one month. ${ }^{21}$ Tumour response was assessed based on radiological evaluation according to the modified Response Evaluation Criteria in Solid Tumors (mRECIST). The oncological outcomes of this study were death and recurrence. OS was calculated from the date of the first session of CRA treatment for subcardiac HCC to the date of death or the date of the last follow-up (survival or loss). RFS was calculated from the date of the first session of CRA treatment for subcardiac HCC to the date of recurrence or the date of the last follow-up (survival or loss). Major complications were defined as events that caused substantial morbidity and disability that increased the level of care, led to hospital admission, or substantially prolonged the hospital stay. ${ }^{22}$

\section{Statistical Analysis}

SPSS 21.0 software (SPSS, Chicago, IL) was used to perform statistical analyses. The quantitative data are expressed as the mean \pm standard deviation, while the qualitative data are expressed as the frequency. Pearson $\chi^{2}$ analysis or Fisher's exact test was executed for categorical variable comparisons. Continuous variables that fulfilled the normality assumption were compared using the two sample $t$ test; otherwise, the Mann-Whitney $U$-test 
was performed. The Kaplan-Meier method with the Log rank test was used to evaluate OS and RFS. Significant effects of multiple factors on the survival rate were identified by a Cox proportional hazards model. For all tests, a $\mathrm{P}$ value $<0.05$ was considered statistically significant.

\section{Results}

\section{Baseline Characteristics}

A total of 73 consecutive patients with single subcardiac HCC who underwent CT-PCRA were retrospectively reviewed. The median follow-up time was 37.8 months. In addition, 7 patients with nodules $>4 \mathrm{~cm}$ in diameter underwent transarterial chemoembolization (TACE) before CT-PCRA. Of these patients, 20 died, and 34 experienced recurrence. The characteristics of the patients and tumours are summarized in Table 1 . The majority of the patients were male and had hepatitis B virus infection and cirrhosis; there were no significant differences between the subcardiac and non-subcardiac HCC groups $(\mathrm{p}=$ $0.490, p=0.644$ and $p=0.542$ ). Among the cases of subcardiac HCC, 21 were located on segment IV, and the remaining were located on segments II or III. The laboratory test results were as follows: the median AFP was $155.6 \mathrm{ng} / \mathrm{mL}(8.4-1236.9 \mathrm{ng} /$ $\mathrm{mL}$ ), the median ALT was $35.6 \mathrm{U} / \mathrm{L}(11.3-452.6 \mathrm{U} / \mathrm{L})$, the median AST was 37.2 U/L (9.2-239.2 U/L), the median albumin was $37.8 \mathrm{~g} / \mathrm{L}(30.7-58.1 \mathrm{~g} / \mathrm{L})$ and the median bilirubin was $13.5 \mathrm{~g} / \mathrm{L}(5.0-141.9 \mathrm{~g} / \mathrm{L})$ in the subcardiac HCC group; the laboratory results were comparable with those in the nonsubcardiac HCC group.

\section{Treatment Efficacy}

The details of the treatment efficacy of CT-PCRA in subcardiac HCC patients are shown in Table 2. Based on the follow-up imaging, the technical success rate of CT-PCRA for subcardiac HCC was $93.9 \%$ (31/33), which was comparable with that of subcardiac HCC $(p=1.000)$. The reason for the technical failure was incomplete tumour ablation $(\mathrm{n}=2)$ due to the technical difficulty of the procedure; both residual cases underwent a second CT-PCRA. Moreover, the number of patients with complete response (CR) was 7, partial response (PR) was 21 , stable disease $(\mathrm{SD})$ was 3 , and progressive disease $(\mathrm{PD})$ was 2 in the subcardiac HCC group. The objective response rate (ORR) was $77.8 \%$ (28/33), which was comparable with that of the non-subcardiac HCC group ( $p=0.590)$. As three types of recurrence, LTP, IDR and EDR were found at 2 months, 13 months and 1 month after CT-PCRA. Of these patients, 11 underwent CRA, 2 underwent MWA, 1 underwent RFA, 2 underwent $\mathrm{SR}$, and 1 refused to receive additional treatment.
Table I Baseline Characteristics

\begin{tabular}{|c|c|c|c|}
\hline Characteristics & $\begin{array}{l}\text { Subcardiac } \\
\text { HCC Group } \\
(n=33)\end{array}$ & $\begin{array}{l}\text { Non-Subcardiac } \\
\text { HCC Group } \\
(n=40)\end{array}$ & $P$ value \\
\hline Age (year), Mean \pm SD (Range) & $59.3 \pm 10.3(32-76)$ & $58.2 \pm \mid 1.5(35-78)$ & 0.283 \\
\hline $\begin{array}{l}\text { Gender } \\
\text { Male } \\
\text { Female }\end{array}$ & $\begin{array}{l}26(78.8) \\
7(21.2)\end{array}$ & $\begin{array}{l}34(85.0) \\
6(15.0)\end{array}$ & 0.490 \\
\hline $\begin{array}{l}\text { Etiology } \\
\text { HBV } \\
\text { HCV } \\
\text { No hepatitis }\end{array}$ & $\begin{array}{l}29(87.8) \\
2(6.1) \\
2(6.1)\end{array}$ & $\begin{array}{l}33(82.5) \\
5(12.5) \\
2(5.0)\end{array}$ & 0.644 \\
\hline $\begin{array}{l}\text { Comorbidities } \\
\text { Yes } \\
\text { No }\end{array}$ & $\begin{array}{l}20(60.6) \\
13(39.4)\end{array}$ & $\begin{array}{l}30(75.0) \\
10(25.0)\end{array}$ & 0.188 \\
\hline $\begin{array}{l}\text { Cirrhosis } \\
\text { Yes } \\
\text { No }\end{array}$ & $\begin{array}{l}31(93.9) \\
2(6.1)\end{array}$ & $\begin{array}{l}36(90.0) \\
4(20.0)\end{array}$ & 0.542 \\
\hline $\begin{array}{l}\text { Tumor size }(\mathrm{cm}) \text {, mean } \pm \\
\text { SD (range) } \\
\quad<3 \\
\geq 3\end{array}$ & $\begin{array}{l}2.6 \pm 0.7(0.8-5) \\
21(63.6) \\
12(36.4)\end{array}$ & $\begin{array}{l}2.5 \pm 1.0(0.9-5) \\
31(77.5) \\
9(22.5)\end{array}$ & 0.673 \\
\hline $\begin{array}{l}\text { Differentiation } \\
\text { Low } \\
\text { Moderate }\end{array}$ & $\begin{array}{l}18(54.5) \\
15(45.5)\end{array}$ & $\begin{array}{l}25(62.7) \\
15(37.5)\end{array}$ & 0.492 \\
\hline $\begin{array}{l}\text { AFP level (ng/mL), median } \\
\text { (range) } \\
\text { ALT (U/L), median (range) } \\
\text { AST (U/L), median (range) } \\
\text { Albumin }(g / L) \text {, median (range) } \\
\text { Bilirubin (g/L), median (range) }\end{array}$ & $\begin{array}{l}155.6(8.4-1236.9) \\
35.6(11.3-452.6) \\
37.2(9.2-239.2) \\
37.8(30.7-58.1) \\
13.5(5.0-141.9)\end{array}$ & $\begin{array}{l}127.5(9.1-3390.2) \\
36.2(9.8-290.3) \\
34.4(6.3-182.3) \\
39.0(32.9-46.1) \\
10.2(5.4-130.2)\end{array}$ & $\begin{array}{l}0.398 \\
0.342 \\
0.192 \\
0.593 \\
0.230\end{array}$ \\
\hline $\begin{array}{l}\text { CTP Grade } \\
\text { A } \\
\text { B }\end{array}$ & $\begin{array}{l}31(93.9) \\
2(6.1)\end{array}$ & $\begin{array}{l}39(97.5) \\
I(2.5)\end{array}$ & 0.586 \\
\hline $\begin{array}{l}\text { ALBI Grade } \\
\qquad \begin{array}{l}\text { I } \\
2-3\end{array}\end{array}$ & $\begin{array}{l}27(81.8) \\
6(18.2)\end{array}$ & $\begin{array}{l}35(87.5) \\
5(12.5)\end{array}$ & 0.530 \\
\hline $\begin{array}{l}\text { Follow-up (months), median } \\
\text { (range) }\end{array}$ & $37.8(23.2-71.7)$ & $37.8(23.2-71.7)$ & 0.727 \\
\hline
\end{tabular}

Note: Unless otherwise indicated, numbers in parentheses are the percentage.

Abbreviations: $S D$, standard deviation. $H B V$, hepatitis $B$ virus; $H C V$, hepatitis $C$ virus; CTP, child-turcotte-pugh; AFP, $\alpha$-fetoprotein; AST, aspartate aminotransferase; ALT, alanine aminotransferase; INR, international normalized ratio; ALBI, albumin- bilirubin.

\section{Oncological Outcomes and Risk Factors After CT-PCRA}

After a median follow-up time of 37.8 months, the cumulative 1-, 3- and 5-year OS rates were $84.4 \%, 70.3 \%$ and $70.3 \%$, respectively, in the subcardiac $\mathrm{HCC}$ group and $85.2 \%, 70.8 \%$ and $70.8 \%$ in the non-subcardiac $\mathrm{HCC}$ group (Figure 3A). There were no statistically significant 
Table 2 Treatment Efficacy After CT-PCRA for SHCC

\begin{tabular}{|l|l|l|l|}
\hline Treatment Efficacy & $\begin{array}{l}\text { SHCC Group } \\
(\mathbf{n}=\mathbf{3 3})\end{array}$ & $\begin{array}{l}\text { Non-SHCC } \\
\text { Group } \mathbf{( n = 4 0 )}\end{array}$ & P value \\
\hline $\begin{array}{l}\text { Technical Success } \\
\text { Yes }\end{array}$ & $31(93.9)$ & $38(95.0)$ & 1.000 \\
No & $2(6.1)$ & $2(5.0)$ & \\
\hline $\begin{array}{l}\text { Tumor Response } \\
\text { ORR }\end{array}$ & $28(77.8)$ & $32(80.0)$ & 0.590 \\
CR & $7(21.2)$ & $12(30.0)$ & \\
PR & $21(63.6)$ & $20(50.0)$ & \\
SD & $3(9.1)$ & $5(12.5)$ & \\
PD & $2(6.2)$ & $3(7.5)$ & \\
\hline Oncological Outcomes & & & \\
Death & $9(27.2)$ & $11(27.5)$ & 0.983 \\
Recurrence & $16(48.5)$ & $18(45.0)$ & 0.766 \\
LTP & $2(6.2)$ & $2(2.0)$ & \\
IDR & $13(39.4)$ & $14(35.0)$ & \\
EDR & $1(3.1)$ & $3(7.5)$ & \\
\hline Treatment in Recurrence & & & \\
SR & $2(6.2)$ & $1(2.5)$ & \\
MWA & $2(6.2)$ & $1(2.5)$ & \\
RFA & $1(3.1)$ & $2(5.0)$ & $14(87.5)$ \\
CRA & $1 I(33.2)$ & $1(2.5)$ & \\
TACE & $0(0)$ & $0(0)$ & \\
Refuse treatment & $1(3.1)$ & \\
\hline
\end{tabular}

Note: Unless otherwise indicated, numbers in parentheses are the percentage. Abbreviations: $S D$, standard deviation. ORR, objective response rate; $C R$, complete response; PR, partial response; SD, stable disease; PD, progressive disease. RFA, radiofrequency ablation; MWA, microwave ablation; TACE, transarterial chemoembolization; SR, surgical resection; CRA, cryoablation.

differences between the two groups $(\mathrm{p}=0.822)$. The cumulative 1-, 3- and 5-year RFS rates were $67.6 \%, 39.0 \%$ and $26.9 \%$, respectively, in the subcardiac HCC group and $68.5 \%, 36.6 \%$ and $36.6 \%$, in the non-subcardiac HCC group (Figure 3B). There were no statistically significant differences between the two groups $(p=0.920)$. Univariate and multivariate logistic regression analyses were performed to identify predictors influencing the long-term outcome of patients with subcardiac HCC who underwent CTPCRA. The univariate analysis showed statistically significant differences in terms of OS rates, depending on age (hazard ratio [HR]: $1.257,95 \%$ confidence interval [CI]: 1.637-4.324; $\mathrm{p}=0.007$ ) and ALBI grade (HR: 2.024, 95\% CI: $1.302-4.294 ; \mathrm{p}=0.038)$. The multivariate analysis showed that older age (HR: 2.382, 95\% CI: 1.884-7.823; $\mathrm{p}=0.002$ ) and ALBI grade 2-3 (HR: 3.398, 95\% CI: $1.950-6.058 ; \mathrm{p}=0.021)$ may be predictors of poor OS. (Table 3 ). The univariate analysis showed statistically significant differences in terms of RFS rates depending on tumour size (HR: $2.916,95 \%$ CI: $1.562-5.274 ; p=0.034$ ). The multivariate analysis showed that tumour size $\geq 3 \mathrm{~cm}$ in diameter (HR: $3.302,95 \%$ CI: $2.232-8.293 ; \mathrm{p}=0.012$ ) may be a predictor of poor RFS (Table 4).

\section{Complications}

No CT-PCRA-related deaths occurred. Among patients with subcardiac HCC, major complications related to the CRA procedure were observed in $2(6.1 \%)$, including intra-abdominal bleeding and right pleural effusion at 2.2 and 3.1 months, which were comparable with those of non-subcardiac HCC patients $(p=0.683)$. Minor complications were observed in 13 (39.4\%) patients, including mild abdominal pain, fever, nausea, vomiting, thrombocytopenia, and local superficial partial-thickness frostbite, which were comparable with those of non-subcardiac HCC patients $(\mathrm{p}=0.487)$. All minor complications were transient and resolved within one week (Table 5). The mean pain scores according to the visual analogue scale (VAS) at 2 h, 1 day, 2 days and 3 days after CRA were

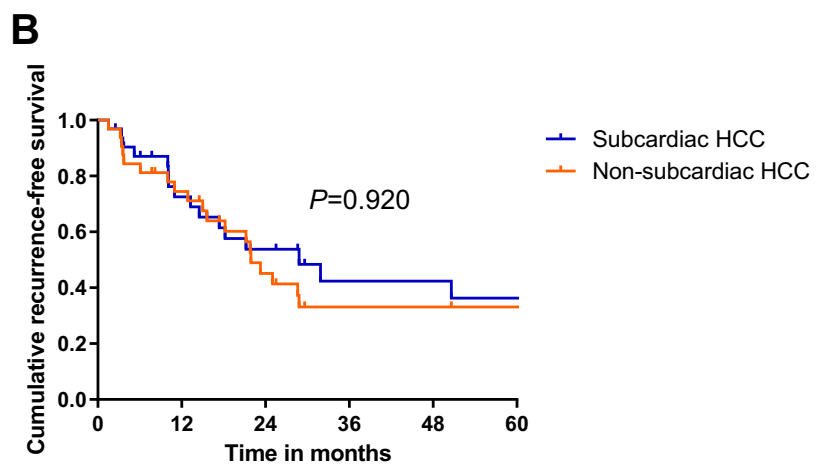

Figure 3 Kaplan-Meier curves showed that comparation of cumulative overall survival (OS) and recurrence-free survival (RFS) rate between subcardiac HCC and nonsubcardiac HCC group. (A) cumulative I-, 3-, 5- years OS rate were $76.4 \%, 70.3 \%$ and $70.3 \%$ in subcardiac $\mathrm{HCC}$ group and $76.4 \%, 70.3 \%$ and $70.3 \%$ in non-subcardiac $\mathrm{HCC}$ group. There were no significant differences between two groups ( $\mathrm{p}=0.822)$; $(\mathbf{B})$ cumulative $1-, 3-, 5$ - years RFS rate were $76.4 \%, 70.3 \%$ and $70.3 \%$ in subcardiac HCC group and $76.4 \%, 70.3 \%$ and $70.3 \%$ in non-subcardiac HCC group. There were no significant differences between two groups ( $p=0.920)$. 
Table 3 Factors Associated with OS After CT-PCRA for EHCC

\begin{tabular}{|c|c|c|c|c|}
\hline \multirow[t]{2}{*}{ Factor } & \multicolumn{2}{|l|}{ Univariate Analysis } & \multicolumn{2}{|c|}{ Multivariate Analysis } \\
\hline & HR $(95 \% \mathrm{Cl})$ & $P$ value & HR (95\% Cl) & $P$ value \\
\hline $\begin{array}{l}\text { Age (years) } \\
\quad<65 \\
\geq 65\end{array}$ & $\begin{array}{l}1.257(1.637,4.324) \\
21 \\
12\end{array}$ & 0.007 & $\begin{array}{l}2.382(1.884, \\
7.823) \\
21 \\
12\end{array}$ & 0.002 \\
\hline $\begin{array}{l}\text { Gender } \\
\text { Male } \\
\text { Female }\end{array}$ & $\begin{array}{l}1.783(0.838,4.034) \\
26 \\
7\end{array}$ & 0.903 & $\begin{array}{l}\cdots \\
26 \\
7\end{array}$ & $\ldots$ \\
\hline $\begin{array}{l}\text { Comorbidities } \\
\text { Positive } \\
\text { Negative }\end{array}$ & $\begin{array}{l}2.403(0.934,3.134) \\
20 \\
13\end{array}$ & 0.673 & $\begin{array}{l}\ldots \\
20 \\
13\end{array}$ & .. \\
\hline $\begin{array}{c}\text { Cirrhosis } \\
\text { Positive } \\
\text { Negative }\end{array}$ & $\begin{array}{l}1.578(0.758,4.403) \\
31 \\
2\end{array}$ & 0.793 & $\begin{array}{l}\cdots \\
31 \\
2\end{array}$ & $\ldots$ \\
\hline $\begin{array}{l}\text { Hepatitis } \\
\text { B surface antigen } \\
\text { Positive } \\
\text { Negative }\end{array}$ & $\begin{array}{l}2.512(0.368,4.447) \\
29 \\
4\end{array}$ & 0.442 & $\begin{array}{l}\cdots \\
29 \\
4\end{array}$ & $\ldots$ \\
\hline $\begin{array}{l}\text { Tumor size }(\mathrm{cm}) \\
\quad<3 \\
\geq 3\end{array}$ & $\begin{array}{l}1.916(0.776,4.384) \\
21 \\
12\end{array}$ & 0.612 & $\begin{array}{l}\cdots \\
21 \\
12\end{array}$ & $\ldots$ \\
\hline $\begin{array}{l}\alpha \text {-fetoprotein level } \\
(\mathrm{ng} / \mathrm{mL} \text { ) } \\
\quad \leq 20 \\
>20\end{array}$ & $\begin{array}{l}2.920(0.834,4.123) \\
27 \\
6\end{array}$ & 0.445 & $\begin{array}{l}27 \\
6\end{array}$ & $\theta$ \\
\hline $\begin{array}{l}\text { Child-Pugh grade } \\
\text { A } \\
\text { B }\end{array}$ & $\begin{array}{l}2.302(0.784,4.452) \\
31 \\
2\end{array}$ & 0.393 & $\begin{array}{l}\cdots \\
31 \\
2\end{array}$ & $\ldots$ \\
\hline $\begin{array}{l}\text { ALBI grade } \\
1 \\
2-3\end{array}$ & $\begin{array}{l}2.024(1.302,4.294) \\
27 \\
6\end{array}$ & 0.038 & $\begin{array}{l}3.398(1.950, \\
6.058) \\
27 \\
6\end{array}$ & 0.021 \\
\hline
\end{tabular}

Notes: Data in parentheses are $95 \%$ confidence intervals. Variables were analyzed by a univariate model of Cox Proportional Hazard Test; those with a P-value $<0.05$ were showed here and were forwarded to the multivariate analysis.

Abbreviations: OS, overall survival; EHCC, subcardiac hepatocellular carcinoma; CT-PCRA, computed tomography-guided percutaneous cryoablation; ALBI, albumin-bilirubin.

$2.03 \pm 1.17,0.78 \pm 0.21,0.56 \pm 0.11$, and $0.04 \pm 0.17$, respectively. There was no arrhythmia or tachycardia or any symptoms of ischaemic heart disease.

\section{Discussion}

For patients with subcardiac HCC, reasonable treatment strategies have always been difficult and challenging for interventionalists when thermal ablation procedures are performed. The reason is that the thermal field range is difficult to control, so doctors dare not overuse. CRA
Table 4 Factors Associated with RFS After CT-PCRA for EHCC

\begin{tabular}{|c|c|c|c|c|}
\hline \multirow[t]{2}{*}{ Factor } & \multicolumn{2}{|l|}{ Univariate Analysis } & \multicolumn{2}{|c|}{ Multivariate Analysis } \\
\hline & HR $(95 \% \mathrm{Cl})$ & $P$ value & HR $(95 \% \mathrm{Cl})$ & $P$ value \\
\hline $\begin{array}{l}\text { Age (years) } \\
\quad<65 \\
\geq 65\end{array}$ & $\begin{array}{l}0.932(0.427,3.336) \\
21 \\
12\end{array}$ & 0.782 & $\begin{array}{l}\cdots \\
21 \\
12\end{array}$ & $\ldots$ \\
\hline $\begin{array}{l}\text { Gender } \\
\text { Male } \\
\text { Female }\end{array}$ & $\begin{array}{l}1.478(0.058,3.362) \\
26 \\
7\end{array}$ & 0.246 & $\begin{array}{l}\cdots \\
26 \\
7\end{array}$ & $\ldots$ \\
\hline $\begin{array}{l}\text { Comorbidities } \\
\text { Positive } \\
\text { Negative }\end{array}$ & $\begin{array}{l}1.478(0.058,3.362) \\
20 \\
13\end{array}$ & 0.246 & $\begin{array}{l}20 \\
13\end{array}$ & \\
\hline $\begin{array}{l}\text { Cirrhosis } \\
\text { Positive } \\
\text { Negative }\end{array}$ & $\begin{array}{l}1.478(0.058,3.362) \\
31 \\
2\end{array}$ & 0.246 & $\begin{array}{l}31 \\
2\end{array}$ & \\
\hline $\begin{array}{l}\text { Hepatitis } \\
\text { B surface antigen } \\
\text { Positive } \\
\text { Negative }\end{array}$ & $\begin{array}{l}2.227(0.568,4.447) \\
29 \\
4\end{array}$ & 0.459 & $\begin{array}{l}\cdots \\
29 \\
4\end{array}$ & $\ldots$ \\
\hline $\begin{array}{l}\text { Tumor size (cm) } \\
\quad<3 \\
\geq 3\end{array}$ & $\begin{array}{l}2.916(1.562,5.274) \\
21 \\
12\end{array}$ & 0.034 & $\begin{array}{l}3.302(2.232, \\
8.293) \\
21 \\
12\end{array}$ & 0.012 \\
\hline $\begin{array}{l}\alpha \text {-fetoprotein level } \\
(\mathrm{ng} / \mathrm{mL}) \\
\leq 200 \\
>200\end{array}$ & $\begin{array}{l}0.884(0.271,1.193) \\
27 \\
6\end{array}$ & 0.445 & $\begin{array}{l}\cdots \\
27 \\
6\end{array}$ & $\ldots$ \\
\hline $\begin{array}{l}\text { Child-Pugh grade } \\
\text { A } \\
\text { B }\end{array}$ & $\begin{array}{l}1.012(0.332,3.192) \\
31 \\
2\end{array}$ & 0.093 & $\begin{array}{l}\cdots \\
31 \\
2\end{array}$ & $\ldots$ \\
\hline $\begin{array}{l}\text { ALBI grade } \\
\begin{array}{l}1 \\
2-3\end{array}\end{array}$ & $\begin{array}{l}1.398(0.950,2.058) \\
27 \\
6\end{array}$ & 0.401 & $\begin{array}{l}\cdots \\
27 \\
6\end{array}$ & $\ldots$ \\
\hline $\begin{array}{l}\text { Sessions } \\
1 \\
>1\end{array}$ & $\begin{array}{l}1.478(0.058,3.362) \\
30 \\
3\end{array}$ & 0.246 & $\begin{array}{l}\cdots \\
30 \\
3\end{array}$ & $\ldots$ \\
\hline
\end{tabular}

Notes: Data in parentheses are $95 \%$ confidence intervals. Variables were analyzed by a univariate model of Cox Proportional Hazard Test; those with a $P$-value $<0.05$ were showed here and were forwarded to the multivariate analysis.

Abbreviations: RFS, recurrence-free survival; EHCC, subcardiac hepatocellular carcinoma; CT-PCRA, computed tomography-guided percutaneous cryoablation; ALBI, albumin-bilirubin.

provides two important potential advantages over other modes of heat-induced ablation, including MWA and RFA. ${ }^{23-25}$ First, CRA provides a larger ice ball generated from multiple simultaneous cryoprobes. Second, CRA can be clearly identified when submitted to intraprocedural CT, and a clear boundary and the shape of the generated ice ball can be observed. Our team used CT-PCRA for subcardiac HCC treatment in several cases. Subsequently, we 
Table 5 Complications After CT-PCRA for SHCC

\begin{tabular}{|c|c|c|c|}
\hline Complications & $\begin{array}{l}\text { Subcardiac } \\
\text { HCC Group } \\
(n=33)\end{array}$ & $\begin{array}{l}\text { Non- } \\
\text { Subcardiac } \\
\text { HCC Group } \\
(n=40)\end{array}$ & $P$ value \\
\hline $\begin{array}{l}\text { Major Complications } \\
\text { Intra-abdominal } \\
\text { bleeding } \\
\text { Haemorrhage } \\
\text { Pleural effusion } \\
\text { Severe ascites } \\
\text { Abscess }\end{array}$ & $\begin{array}{l}\text { I (3.0) } \\
- \\
\text { I (3.0) } \\
- \\
-\end{array}$ & $\begin{array}{l}- \\
- \\
2(5.0) \\
- \\
2(5.0)\end{array}$ & 0.683 \\
\hline $\begin{array}{l}\text { Minor Complications } \\
\text { Fever } \\
\text { Pain } \\
\text { Nausea } \\
\text { Vomit } \\
\text { Thrombocytopenia } \\
\text { Local superficial } \\
\text { partial-thickness } \\
\text { frostbite }\end{array}$ & $\begin{array}{l}3(9.1) \\
7(2 \mid .2) \\
\text { I }(3.0) \\
- \\
\text { I (3.0) } \\
\text { I (3.0) }\end{array}$ & $\begin{array}{l}5(12.5) \\
12(30.0) \\
2(5.0) \\
- \\
- \\
-\end{array}$ & 0.487 \\
\hline
\end{tabular}

Note: Unless otherwise indicated, numbers in parentheses are the percentage.

retrospectively analysed the efficacy and safety of this ablation technology.

Numerous large case series have recommended that topographic factors may prevent the RFA local tumour control of HCC. ${ }^{26-28}$ Likewise, Cha et al reported ${ }^{19}$ that HCC in high-risk locations, such as subcardiac tumours, is a risk factor for postablation complications. Recurrence and severe complications after ablation were unavoidable when HCC nodules abutting the heart were found. Nevertheless, the present study found that the technical success rate (33/36 tumours; 91.6\%) and ORR (28/36 tumours; $77.8 \%$ ) in the subcardiac HCC group were relatively high. Therefore, this study shows that CT-PCRA for subcardiac HCC is a successful and feasible treatment in terms of the technical success rate and ORR, which were comparable to those of non-subcardiac HCC. These results also suggest that nodules abutting the heart are not a risk factor for CT-PCRA technical failure.

This study also showed that the 5-year OS and RFS rates were $70.3 \%$ and $26.9 \%$, respectively, in patients with subcardiac HCC and that these data are comparable with those of non-subcardiac HCC patients. Previously, Rong et al showed that 866 patients with HCC who met the Milan criteria underwent CRA had cumulative OS and LTP rates of $59.5 \%$ and $24.2 \%$, respectively, over 5 years. ${ }^{29}$ Advanced age, multiple injuries and a family history of HCC were identified as independent significant negative predictors of OS after CRA. Here, we observed the survival outcome after CT-PCRA in patients with subcardiac HCC based mainly on age and ALBI grade. These findings are consistent with results from previous studies. ALBI is an objective and simple method for assessing liver function associated with overall mortality, ${ }^{30}$ which may explain the importance of maintaining hepatic function reserve. In addition, larger tumour size was an indicator of recurrence after CT-PCRA, similar to the findings of previous studies. . $^{14,15,31}$

CRA can interfere with cardiac conductivity, although arrhythmias associated with this procedure rarely occur. However, very low temperatures may cause haemorrhagic cardiac tamponade. This study found two severe complications after the CT-PCRA procedure in the subcardiac HCC group, similar to that in the non-subcardiac HCC group. Fortunately, no tachycardia, arrhythmia or symptoms of ischaemic heart disease were observed in the two HCC groups undergoing the CRA procedure. Although the $6.1 \%$ occurrence rate observed here is higher than the $4.1 \%$ occurrence rate previously obtained by Cha et al, ${ }^{19}$ this may be attributed mainly to the performance of CRA without any assistive technology, such as hydrodissection. The continuous movement of the heart can avoid constant contact of the heart with the low temperatures from the CRA electrode during ablation. Assistive technology and continuous heart movement may be key factors in preventing heart frostbite in subcardiac HCC patients. On the other hand, the continuous movement of the heartbeats can oscillate the liver and cause direct unwanted damage to the heart by the sharp tip of the electrode, even if it is kept in place. Therefore, careful planning before treatment in subcardiac HCC patients is essential, and the CRA electrode pathway must be checked to be safe and to prevent the electrode tip from moving towards the heart while it is inserted. If this is not possible, other procedural options, such as radiation therapy and TACE, may be considered.

The present study highlights that CRA can obtain similar results in subcardiac HCC patients and may be a new treatment option for HCC ablation in this highrisk location. However, this study has some limitations. First, this study evaluated a relatively small series of patients. A limited sample size and the retrospective nature of this study may reduce the statistical power of the comparative analysis, so that some associations may not have been detected. In addition, all patients in our 
cohort were treated at the same medical centre, and therefore, it is difficult to exclude any bias completely. Finally, ablation success was evaluated by radiographic findings in relation to pathologic margin-free status. Although intermediate follow-up was reported, radiographic techniques may take longer to detect failures in ablation.

In conclusion, CT-PCRA treatment for subcardiac HCC patients can be performed safely and effectively and contribute to improving the survival prognosis. At the time of preoperative planning, special concern is needed to reduce the recurrence rate of the procedure when the patient has a larger tumour size (diameter $>3 \mathrm{~cm}$ ).

\section{Data Sharing Statement}

Please contact the corresponding author for all data requests and the data related with CT-PCRA for subcardiac HCC is confidential.

\section{Author Contributions}

All authors contributed to data analysis, drafting or revising the article, gave final approval of the version to be published, and agree to be accountable for all aspects of the work.

\section{Disclosure}

The authors declare no conflicts of interest in this work.

\section{References}

1. Bray F, Ferlay J, Soerjomataram I, Siegel RL, Torre LA, Jemal A. Global cancer statistics 2018: GLOBOCAN estimates of incidence and mortality worldwide for 36 cancers in 185 countries. CA Cancer J Clin. 2018;68(6):394-424. doi:10.3322/caac.21492

2. Siegel RL, Miller KD, Jemal A. Cancer statistics, 2020. CA Cancer J Clin. 2020;70(1):7-30. doi:10.3322/caac.21590

3. Forner A, Reig M, Bruix J. Hepatocellular carcinoma. Lancet. 2018;391(10127):1301-1314. doi:10.1016/S0140-6736(18)30010-2

4. Ng K, Cheung TT, Wong T, et al. Long-term survival comparison between primary transplant and upfront curative treatment with salvage transplant for early stage hepatocellular carcinoma. Asian J Surg. 2019;42(2):433-442. doi:10.1016/j.asjsur.2018.08.008

5. Dimitroulis D, Damaskos C, Valsami S, et al. From diagnosis to treatment of hepatocellular carcinoma: an epidemic problem for both developed and developing world. World J Gastroenterol. 2017;23 (29):5282-5294. doi:10.3748/wjg.v23.i29.5282

6. Li JK, Liu XH, Cui H, Xie XH. Radiofrequency ablation vs. surgical resection for resectable hepatocellular carcinoma: a systematic review and meta-analysis. Mol Clin Oncol. 2020;12(1):15-22. doi:10.3892/ mco.2019.1941

7. Chen J, Lin Z, Lin Q, Lin R, Yan Y, Chen J. Percutaneous radiofrequency ablation for small hepatocellular carcinoma in hepatic dome under MR-guidance: clinical safety and efficacy. Int J Hyperthermia. 2020;37 (1):192-201. doi:10.1080/02656736.2020.1728397
8. Zhu F, Rhim H. Thermal ablation for hepatocellular carcinoma: what's new in 2019. Chin Clin Oncol. 2019;8(6):58. doi:10.21037/ cco.2019.11.03

9. Filippiadis DK, Spiliopoulos S, Konstantos C, et al. Computed tomography-guided percutaneous microwave ablation of hepatocellular carcinoma in challenging locations: safety and efficacy of high-power microwave platforms. Int J Hyperthermia. 2018;34 (6):863-869. doi:10.1080/02656736.2017.1370728

10. An C, Cheng Z, Yu X, et al. Ultrasound-guided percutaneous microwave ablation of hepatocellular carcinoma in challenging locations: oncologic outcomes and advanced assistive technology. Int J Hyperthermia. 2020;37(1):89-100. doi:10.1080/02656736.2019.1711203

11. Yang Y, Zhang Y, Wu Y, et al. Efficacy and safety of percutaneous argon-helium cryoablation for hepatocellular carcinoma abutting the diaphragm. J Vasc Interv Radiol. 2020;31(3):393400.e1. doi:10.1016/j.jvir.2019.11.003

12. Cha SY, Kang TW, Min JH, et al. RF ablation versus cryoablation for small perivascular hepatocellular carcinoma: propensity score analyses of mid-term outcomes. Cardiovasc Intervent Radiol. 2020;43 (3):434-444. doi:10.1007/s00270-019-02394-4

13. Wang F, Ma J, Wu L, et al. Percutaneous cryoablation of subcapsular hepatocellular carcinoma: a retrospective study of 57 cases. Diagn Interv Radiol. 2020;26(1):34-39. doi:10.5152/dir.2019.18543

14. Ei S, Hibi T, Tanabe M, et al. Cryoablation provides superior local control of primary hepatocellular carcinomas of $>2 \mathrm{~cm}$ compared with radiofrequency ablation and microwave coagulation therapy: an underestimated tool in the toolbox. Ann Surg Oncol. 2015;22 (4):1294-1300. doi:10.1245/s10434-014-4114-7

15. Song KD. Percutaneous cryoablation for hepatocellular carcinoma. Clin Mol Hepatol. 2016;22(4):509-515. doi:10.3350/cmh.2016.0079

16. Lin $\mathrm{CH}, \mathrm{Ho} \mathrm{CM}$, Wu $\mathrm{CH}$, et al. Minimally invasive surgery versus radiofrequency ablation for single subcapsular hepatocellular carcinoma $\leq 2 \mathrm{~cm}$ with compensated liver cirrhosis. Surg Endosc. 2020. doi:10.1007/s00464-019-07357-x

17. Worakitsitisatorn A, Lu DS, Lee MW, et al. Percutaneous thermal ablation of subcapsular hepatocellular carcinomas: influence of tumor-surface contact and protrusion on therapeutic efficacy and safety. Eur Radiol. 2019.

18. Petit A, Hocquelet A, N'kontchou G, et al. No-touch multi-bipolar radiofrequency ablation for the treatment of subcapsular hepatocellular carcinoma $\leq 5 \mathrm{~cm}$ not puncturable via the non-tumorous liver parenchyma. Cardiovasc Intervent Radiol. 2020;43(2):273-283. doi:10.1007/s00270-019-02357-9

19. Cha DI, Kang TW, Song KD, et al. Radiofrequency ablation for subcardiac hepatocellular carcinoma: therapeutic outcomes and risk factors for technical failure. Eur Radiol. 2019;29(5):2706-2715. doi:10.1007/s00330-018-5868-2

20. Chong C, Lee KF, Chu CM, et al. Microwave ablation provides better survival than liver resection for hepatocellular carcinoma in patients with borderline liver function: application of ALBI score to patient selection. HPB (Oxford). 2018;20(6):546-554. doi:10.1016/j. hpb.2017.12.001

21. Ahmed M; Technology Assessment Committee of the Society of Interventional Radiology. Image-guided tumor ablation: standardization of terminology and reporting criteria-a 10-year update: supplement to the consensus document. J Vasc Interv Radiol. 2014;25 (11):1706-1708. doi:10.1016/j.jvir.2014.09.005

22. Davidson JC, Rahim S, Hanks SE, et al. Society of Interventional Radiology Consensus Guidelines for the Periprocedural Management of Thrombotic and Bleeding Risk in Patients Undergoing Percutaneous Image-Guided Interventions-Part I: review of Anticoagulation Agents and Clinical Considerations: endorsed by the Canadian Association for Interventional Radiology and the Cardiovascular and Interventional Radiological Society of Europe. J Vasc Interv Radiol. 2019;30(8):1155-1167. doi:10.1016/j.jvir.2019.04.016 
23. Ma YY, Chen JB, Shi JJ, Niu LZ, Xu KC. Cryoablation for liver metastasis from solid pseudopapillary tumor of the pancreas: a case report. World J Clin Cases. 2020;8(2):398-403. doi:10.12998/wjcc. v8.i2.398

24. Ma J, Wang F, Zhang W, et al. Percutaneous cryoablation for the treatment of liver cancer at special sites: an assessment of efficacy and safety. Quant Imaging Med Surg. 2019;9(12):1948-1957. doi:10.21037/qims.2019.11.12

25. Das SK, Huang YY, Li B, Yu XX, Xiao RH, Yang HF. Comparing cryoablation and microwave ablation for the treatment of patients with stage IIIB/IV non-small cell lung cancer. Oncol Lett. 2020;19 (1):1031-1041. doi:10.3892/ol.2019.11149

26. Chen J, Peng K, Hu D, et al. Tumor location influences oncologic outcomes of hepatocellular carcinoma patients undergoing radiofrequency ablation. Cancers (Basel). 2018;10(10):378. doi:10.3390/ cancers 10100378

27. Toshimori J, Nouso K, Nakamura S, et al. Local recurrence and complications after percutaneous radiofrequency ablation of hepatocellular carcinoma: a retrospective cohort study focused on tumor location. Acta Med Okayama. 2015;69(4):219-226. doi:10.18926/ $\mathrm{AMO} / 53558$
28. Kang TW, Lim HK, Lee MW, Kim YS, Choi D, Rhim H. First-line radiofrequency ablation with or without artificial ascites for hepatocellular carcinomas in a subcapsular location: local control rate and risk of peritoneal seeding at long-term follow-up. Clin Radiol. 2013;68(12):e641-51. doi:10.1016/j.crad.2013.07.008

29. Rong G, Bai W, Dong Z, et al. Long-term outcomes of percutaneous cryoablation for patients with hepatocellular carcinoma within Milan criteria. PLoS One. 2015;10(4):e0123065. doi:10.1371/journal. pone. 0123065

30. Safiri S, Ayubi E. Comments on combining albumin-bilirubin score with future liver remnant predicts posthepatectomy liver failure in HBV-associated HCC patients. Liver Int. 2018;38(4):761. doi:10.1111/liv.13542

31. Wang C, Wang H, Yang W, et al. Multicenter randomized controlled trial of percutaneous cryoablation versus radiofrequency ablation in hepatocellular carcinoma. Hepatology. 2015;61 (5):1579-1590. doi:10.1002/hep. 27548

\section{Publish your work in this journal}

Cancer Management and Research is an international, peer-reviewed open access journal focusing on cancer research and the optimal use of preventative and integrated treatment interventions to achieve improved outcomes, enhanced survival and quality of life for the cancer patient.
The manuscript management system is completely online and includes a very quick and fair peer-review system, which is all easy to use. Visit http://www.dovepress.com/testimonials.php to read real quotes from published authors. 